\title{
From Apology to Utopia and The Inner Life of International Law
}

$\underline{\text { Akbar Rasulov }^{*}}$

$\underline{\text { Introduction }}$

A certain body of lore has emerged in recent years around Martti Koskenniemi's 1989 volume 'From Apology to Utopia: The Structure of International Legal Argument' (hereafter FATU). ${ }^{1}$ Stripped to its basics, it tells us that FATU is essentially a work of postmodernist scholarship; ${ }^{2}$ that its intellectual genealogy goes back simultaneously to the Harvard critical legal studies (CLS) tradition and the Yale school of policy science; ${ }^{3}$ that, even though it speaks at such length about the 'ethics of responsibility' and 'reconstructing the rules', ${ }^{4}$ it actually provides a typical illustration of the so-called 'deconstructivist approach'; ${ }^{5}$ that it is a product of a 'rebel[lion] without a cause'; ${ }^{6}$ and that its single most significant contribution to the field of international legal theory lies in its analysis of international law's liberal origins and its discussion of the phenomenon of legal indeterminacy. ${ }^{7}$ In this essay I seek to challenge and displace this set of narratives. My principal aim in doing so is to reclaim what I believe to be FATU's most important theoretical legacy: a highly novel and very powerful argument in defence of the anti-anti-disciplinarian theoretical agenda in the field of academic international legal studies (AILS).

My main objective in these pages is essentially twofold. In the first place, I aim to problematize the traditional image of FATU as 'purely a work of legal theory'. In the second place, I intend also to recover its original intellectual project, by excavating it from beneath that mountain of misreadings and misrememberings under which it has come to be so unceremoniously buried over the last quarter-century. As with every other landmark text, one could argue, of course, that these misintepretations and misreadings have long since become a part of FATU's broader historical identity, an integral element of its 'living meaning'. Be that as it may. It is not my intention in these pages to debate the rights of invented traditions and fabricated memories to endure and persist. Every historical identity is open to renegotiation. Not all misreadings, however well-intentioned or inspired, deserve to go unchallenged. If all interpretation, as Jameson argues, is like 'a Homeric battlefield', and no narrative can be 'effectively disqualified ... by a simple enumeration of inaccuracies or omissions', then the only appropriate response is to attack: 'only another, stronger interpretation can overthrow and refute an interpretation already in place. ${ }^{8}$ Or, as

\footnotetext{
* School of Law, University of Glasgow.

1 MARTTI KOSKENNIEMI, FROM APOLOGy to UtOPiA (1989; rev.edn.2006). All references hereafter are to the revised edition.

2 Andreas Paulus, International Law after Postmodernism, 14 LJIL $727(2001)$.

3 China Mieville, Between Equal Rights 48-50(2005).

4 FATU, 546-61.

5 Iain Scobbie, Towards the Elimination of International Law, 61 BYIL $339(1990)$.

6 Jason Beckett, Rebel without a Cause?, 7 German LJ 1045 (2006).

7 James Crawford, 'Chance, Order, Change', 365 RCADI 115-34(2013); MIEVILLE, supra n. 3, 52-9.

8 Fredric Jameson, The Political Unconscious xiii(2002).
} 
Bourdieu would have said, one has to bend the stick with vigorous enough force if one wants to 'correct the previous bias.'

In the pages ahead I propose a decidedly vigorous interpretation of FATU. The traditional reputation of FATU as a work of postmodern legal scholarship, I contend, is utterly unjustified. To accept it at its face value would be to misunderstand completely not only the broader disciplinary vision its author sought to realise and the highly peculiar legal-theoretic conjuncture in the context of which he developed it, but also the basic theoretical apparatus he deployed in executing his vision and the common genealogy of the various intellectual traditions he recruited for that purpose. Far from being a manifestation of any kind of postmodernist sensibility, I would like to argue, the FATU project, in fact, represents the exact opposite of it. Despite the occasional deployment of some standard postmodernist vocabularies in its introductory pages, in the broader taxonomy of contemporary international legal scholarship FATU belongs firmly on the 'other side of the barricades'. Whatever the author of FATU may have thought about the work of postmodern thinkers as a matter of his private intellectual tastes, as a practitioner of the public craft of international legal scholarship, he was, without a doubt, a card-carrying traditionalist through-andthrough.

The theoretical dimension of my argument has three main parts:

1. Methodological part. In order to understand its specific character as an act of theoretical practice, one must approach FATU not as a symptom of some grand historical process, such as, for instance, the rise of legal structuralism or the arrival of CLS into AILS, but as a direct reflection of its author's immediate individual intra-disciplinary circumstances, including not least his sense of disquiet in the face of an increasing disintegration of international law's traditional epistemological and ideological foundations and his subsequent decision to counter that trend by publishing an academic treatise.

2. Historiographical part. From the historical point of view, it is precisely in these microlevel 'personal' circumstances that one has to search for the key to FATU's basic intellectual project. To put it in a slightly telegraphic fashion: in terms of its overall theoretical design, the FATU project can be essentially said to follow the classical model of Applied Sciences, at the centre of which lies the principle of eradicating the gap between the discourse of academic theory and the discourse of practical knowledge. In the context of AILS, as it came to be understood by FATU's author, the most efficient way to accomplish this objective was to produce a new dual-use analytical framework that could be deployed in practice with equal facility by academic international lawyers and international legal practitioners alike. The sharing of this framework by the two communities, went the implicit assumption, would provide international law with a new platform from which it could rebuild its disintegrating disciplinary and ideological foundations. In the event, the general blueprint for the construction of such a framework was found in the simultaneous execution of three closely interconnected moves: (i) a highly creative re-imagination of the traditional enterprise of legal positivism, ie the legal science move; (ii) the inauguration of the idea that, ontologically speaking, international law is all just one large field of frenzied discursive scrambles, ie the

9 Pierre Bourdieu, In Conversation, 191 NLR 111, 120 (1992). 
discourse theory move; and(iii) the explicit assertion that every such scramble in practice follows a certain set of 'rules of engagement' that apply as unfailingly in the field of doctrinal debates as they do in legal policy discourse, ie the legal semiotics move.

3. The history of legal thought part. Far from being a monument to any kind of postmodernist project, FATU represents the product of an utterly conventional - from the AILS's internal point of view - disciplinary enterprise. Both in terms of its general theoretical ambition and in terms of its specifically jurisprudential aesthetics, the FATU project follows directly in the footsteps of what can be called the study of the inner life of the law tradition. ${ }^{10}$ Historically, the main champions of this tradition were the followers of the late$19^{\text {th }}$-century German legal science and dogmatische Rechtswissenschaft movement. ${ }^{11}$ One also finds its traces, however, in the work of the early $20^{\text {th }}$-century analytical jurisprudes, like Henry Terry and Wesley Hohfeld, and the interwar legal positivists and legal-realist scholars, like Hans Kelsen and Karl Llewellyn. In international law, the equivalent genealogy is slightly more difficult to establish - for most of its history, AILS was a theoretical wasteland - but the main hero-figure here too is Kelsen, accompanied, in later periods, by Myres McDougal and, possibly, Georg Schwarzenberger.

The Ideology of the FATU Project: The Enterprise of Critique and the Challenge of Speaking to Practical Experiences

What was the basic ideology of the FATU project? As tends to be so often the case with such kind of endeavours, the best way to start answering this question would be to turn not to the FATU text itself but to another piece of writing published by the same author: a brief introductory essay he wrote for the 2003 volume of the European Journal of International Law about the life and work of the Danish legal-realist scholar, Alf Ross.

There is a curious passage that appears roughly halfway through it which I think deserves our attention. Here is how it starts:

In some ways, as H.L.A.Hart and others have shown, [the legal] realist insights seem always to be beside the point for answering questions made to practising lawyers. The external perspective offered by realism may increase self-awareness and sharpen critical ability. But it does not provide responses to 'internal' questions about valid law. ... This is why realists did not succeed

\footnotetext{
10 The term 'inner life of the law' comes here from Francis Biddle, but also Karl Marx. Neither of them, admittedly, used it in the exact same sense in which I use it here. See Francis Biddle, Mr. Justice Holmes 61(1942); KarL MarX AND FREDERICK ENGELS, COLLECTED WORKS, VOL. I 260(1975).

11،Legal dogmatics (dogmatische Rechtswissenschaft) - the term frequently used in German to mean the legal science of the law itself as distinguished from such ways of looking upon law from the outside as philosophy, history, or sociology of law.' MAX RHEINSTEIN, MAX WeBER ON LAW IN ECONOMY AND SOCIETY $10(1954)$.
} 
in revolutionising the discipline ... despite all the theoretical fury, and the dismissive tone of voice. ${ }^{12}$

A rather familiar move, it would seem: ever since the days of Oppenheim and McNair, one of the most popular pastimes among international lawyers has been to chide international legal theorists for losing sight of the everyday realities inhabited by their practitioner cousins. But note now where the argument suddenly turns next:

The realists conceived of their enterprise in terms of a fundamental critique. In this they were both right and wrong. They were right to the extent that their insights did undermine much of the academic abstraction that underlay professional routines. ... But they were wrong to think that such a new theory should - or could - have immediately led into new routines, other legal idioms or ways of assessing legal competence. Practising lawyers continued stubbornly to talk about 'sovereignty', 'human rights' or 'binding force'. Somehow, realism failed to answer questions that defined the jobs in which practising lawyers were involved. ${ }^{13}$

How remarkable, this! - to declare that a disciplinary revolution could never be achieved if one only pursued the enterprise of fundamental critique and did not answer those questions in terms of which legal practitioners defined their jobs and constructed their professional lives; to announce that the writing of legal theory may be a project that is as useful as it is a waste of time; that for an international law scholar to focus on subverting the established academic dogmas without creating at the same time new routines and new legal idioms is, effectively, a recipe for professional failure. Let us pause for a moment here. Consider again whose pen these statements come from. This is not some random provincial professor living out his intellectual insecurities in print or a semi-retired ICJ judge venting his anger at history moving too fast for his liking. This is a scholar who by the time he publishes these lines already for more than a decade has been widely recognised as one of the leading international legal theorists of his age, an author whose very first book, infact, opens with the announcement that every foray into international law must of necessity also be an exercise in legal theory. ${ }^{14}$

How can one make sense of this apparent pattern of contradiction? The easiest way to respond to this probably would be to argue something to the effect that the Martti Koskenniemi of 2003' was not really the same person as 'the Martti Koskenniemi of 1989'. Looking at some of the passages in the 2006 epilogue to the Cambridge reissue of FATU, ${ }^{15}$ there certainly would seem to be more than enough evidence to lend support to this argument were one to take it with any degree of seriousness. And yet, as plausible as this

12 Martti Koskenniemi, Introduction: Alf Ross and Life beyond Realism, 14 EJIL 653, 655 (2003).

13 Ibid.,658(italics added).

14 FATU, 1.

15 Consider, for instance, the part where Koskenniemi openly admits that in recent years he had gradually come to realise that the enterprise of legal theory had, in fact, a rather limited purchase since 'international law is not a theoretical discipline' and taking its normative foundations seriously 'has never been its [defining] characteristic'. (Ibid.,600.) 
interpretation may seem in the abstract - it certainly wouldn't be the first time that a prominent international lawyer had had a change of mind about something and decided to advertise that fact in print - I don't find it very convincing. The 'two Koskenniemis' thesis is, to put it simply, a fiction. Whether one takes Professor Koskenniemi's writings from the early 1990s or from the mid-2000s, a very palpable sense of continuity seems to connect all his different projects during this time, both at the level of what one might call their general theoretical economy and in terms of their basic ideological signatures. Indeed, if one looks at the essential logic behind FATU's basic theoretical practice, a very strong case can, in fact, be made that, for all his regular detours into abstract philosophical discussions, the author of FATU would most certainly have agreed with the general message put forward in the Ross essay: it is not the business of any genuinely critical disciplinary project to (only) do critical legal theory.

\section{From 'High Theory' to 'Applied Science': FATU's Place in Contemporary International Legal}

\section{Scholarship}

Unlike most writers who had commented over the years on the legal-realist project, the author of the Ross essay knew exactly what it was that realism failed at. He knew it because he, too, had sought to cross the exact same disciplinary terrain. Where realism had failed, however, he did not.

Unlike the vast majority of AILS scholars before and after him, Martti Koskenniemi did not succeed in developing a legal-theoretic construct that failed to address the intellectual needs of an international legal practitioner. Quite on the contrary: the very first task he had set out to resolve in his career was to tackle precisely that specific challenge.

Consider once again his main claim in the Ross essay. Realism was very successful when it came to undermining the old abstractions of academic thought. Where it failed, though, was in not realising that such a displacement could not by itself automatically trigger the emergence of 'new routines, legal idioms, or ways of assessing legal competence', i.e. the development of precisely those kinds of theoretical products whose main consumers were to be found outside the domain of professional academia. The moment it came to ignore this fact its fate as a disciplinary phenomenon was sealed.

Like so many other movements before and after it, realism had failed to recognise that, structurally, the AILS community has never been the culturally hegemonic sector of the international legal profession(ILP). To induce any kind of disciplinary shift, thus, it could never be enough to focus the thrust of one's efforts only on the plane of the professional academic discourse. It is not in the domain of 'high legal theory' that international law's intellectual culture is produced and articulated. The focal point of one's intervention rather must fall on what Diego Lopez-Medina in a slightly different context calls the order of pop jurisprudence, that is to say, the common juristic sense shared among the non-theoretically proficient segments of the ILP community. ${ }^{16}$ For it is there and there alone that all the

16 See Diego lopez Medina, Teoria impura del Derecho (2004). 
various projects and practices through which the ILP community constitutes itself merge into a single common discursive space.

To get a full sense of FATU's towering achievement as an act of legal scholarship - to glimpse the full scope of its sheer chutzpah and ambition - one must start precisely with this point. What was it that the author of FATU had sought to accomplish in his work? What was it also that separated his intellectual project so radically from everything that came before and after it? The answer to both of these questions is to be found in the idea of pop jurisprudence. What the author of FATU recognised from the very outset - and what the author of the Ross essay later lamented the realists never did - was that the key to winning any kind of intra-disciplinary theoretical struggles in modern international law lies in producing not just a new set of critical-theoretic ideas accessible primarily to professional legal academics, but a new system of intellectual tools and concepts accessible above all to the community of international legal practitioners: a system of tools and concepts which the practising lawyers could use to describe and express their day-to-day professional experiences and anxieties.

For all the conspicuous academicism of its language, FATU, as David Kennedy so correctly reminds us, has managed to pull-off a feat that in the preceding half-century had only ever been attempted once: in the 'early' works of Myres McDougal. ${ }^{17}$ It succeeded in formulating an entirely new reasoning protocol that could be adopted and used with equal facility by legal academics and legal practitioners alike. Crucially, it did this also without drawing at any point on the so-called 'doctrine of sources' tradition, which, as Schachter remarks, has been the main go-to intellectual instrument of the ILP community for most of the last century. ${ }^{18}$

What is more, in developing its vision of a new routine of legal reasoning, FATU also succeeded in developing an entirely new set of analytical idioms for describing, conceptualising, and processing the lived reality of international law - a move whose importance could hardly be overestimated. By supplementing its macro-level theoretic inquiry with the search for a new micro-level analytical vocabulary, FATU went on to pull-off something that back in the day had escaped even Kelsen himself: it presented its readers not only with the general outline of a fundamentally novel way of thinking about international law as a matter of abstract legal theory but also with a perfectly practicable system of conceptual instruments using which they could tackle the twin tasks of dissecting and problematizing all the various practices and experiences in terms of which the international legal practitioner community typically structured its day-to-day existence.

And if all of this had not been enough, on top of everything else, it then also went on to articulate a fundamentally new way of understanding the process of developing and assessing disciplinary competence in contemporary international law. However unpretentious a score this may have seemed on paper, in reality this was truly an achievement of colossal proportions, for it allowed the discipline of AILS for the first time in more than two generations to respond directly to the historic demands not only of the

17 Cf. David Kennedy, The Last Treatise: Project and Person, 7 German LJ 982 (2006).

18 Oscar Schachter, 'International Law in Theory and Practice', 178 RCADI $60-2(1982-V)$. 
immediate internal-ideological processes of the ILP community but also of its broader project of inter-generational self-reproduction. Anyone who has ever used FATU to teach an international law course will recognise immediately the immense intellectual subsidy it provided to international law teachers. The general theory of professional aptitude which FATU outlined supplied a foundation around which it became possible not only to reformulate the conversation about what made international law special or different as a field of practice but also to design any number of new educational curricula to help introduce this field to its newcomers and outsiders.

What made the achievement of such a remarkable feat possible? The answer, I think, should be sought ultimately in FATU's fundamental structure as an intellectual project. More specifically, it has to be sought in its author's explicit endorsement of the general intellectual aesthetics of scientific positivism. ${ }^{19}$ Whatever else it may have sought to achieve, FATU's single most important objective as a work of legal scholarship was to eradicate all visible gaps between 'legal theory', 'legal history', 'doctrinal scholarship', and 'applied legal argument'. The only way in which it could afford to take on that sort of challenge, however, was by actively renouncing the one fundamental tenet shared by every species of postmodern writing: both in terms of its general theoretical organisation and in terms of its basic intellectual ambition, the FATU project energetically and unreservedly endorses the concept of producing a theoretical meta-narrative.

The kind of approach adopted in FATU, explains Koskenniemi, 'seeks only to do what most traditional science has always attempted: to provide a parsimonious theory which can be used to explain a wide range of apparently different types of phenomena under explicated regularities. ${ }^{20}$ The goal pursued by promoting such an approach is not that it should 'permanently solve the lawyer's problems for him'; its main attraction rather comes from the fact that it promises to 'produce a therapeutic effect on lawyers frustrated with their inability to cope with the indeterminacy of theory and the irrelevance of doctrine. ${ }^{21}$ For it is only through alleviating that sort of frustrations that we can ever hope to develop not only a new 'descriptive' but also a new 'normative [account] of the world in which States live': ${ }^{22}$ a roadmap that can lead us 'towards an alternative way of understanding the relationship between law and its neighbouring discourses. ${ }^{23}$

Against the Language Metaphor Reductionism: Understanding the Complexity of FATU's Aspiration

\footnotetext{
19 Not that this should be treated as absolute proof, but that this endorsement was conscious and deliberate is evidenced, inter alia, by Koskenniemi's own later admissions. See, eg, Martti Koskenniemi, Letter to the Editors, 93 AJIL 351 (1999): 'My aim was to examine international law from a standpoint that would be in some ways systematic, perhaps even scientific.'

20 FATU, 13.

21 Ibid.

22 Ibid., 12.

23 Ibid., 13.
} 
One of the most enduring myths about FATU over the years has been the argument that as $a$ work of legal theory its main analytical goal was essentially just to show that international law, in effect, is a quasi-linguistic system that operates according to its own internal logic and is organised according to its own 'rules of grammar'. To prove oneself as a competent international legal professional, follows the argument, one has to learn and master these rules, since it is only by following them that one can produce in practice what other legal professionals would be able to recognise as 'valid' international legal statements, and thus join a discursive tradition accessible exclusively to international lawyers.

Now, to read the FATU project in this light is not, of course, an entirely unjustified response. One can certainly find enough evidence both in the FATU text itself and in the accompanying literature, to give support to this line of interpretation. But not every interpretation that seems supportable in theory is a good one.

For let us face it: the idea that one can think of international law in terms of some hopelessly generalised language/grammar metaphor is not, all things considered, either very interesting or very original. In various guises and forms it has been repeated at least since the mid1950s: one only needs to look at the works of Alf Ross or the young David Kennedy - or for that matter even take a quick peek across the disciplinary divide at some of the early writings by Friedrich Kratochwil - to get a general sense of just how widespread and popular this pattern of thought really is, historically, in the AILS community.

Nor, come to think of it, is this idea really all that theoretically insightful or critically productive. What exactly is one supposed to do as a practising lawyer with the knowledge that international law is built like a language? How is this going to help, say, an international human rights advocate or a foreign office adviser become better at their job? If the only thing that FATU had sought to bring to AILS was the general claim that international law could be analogised to a linguistic system, it is safe to presume none of us today would be devoting so much time and effort to its study.

Certainly, the idea that the workings of the international legal discourse resemble generally those of a linguistically organised system does form an integral part of FATU's broader theoretical argument. But it is definitely not the most important or analytically the most noteworthy part of it. For indeed what sets FATU apart from all the other legal-theoretic projects that have sought over the years to explore the law-language analogy is, of course, the fact that instead of simply putting forward the idea that there may exist such a thing as an international legal grammar, it actually tried to give it flesh. Where others before and after it had stopped at formulating the concept of an international legal semiotics, FATU sought to take the next logical step: by specifying in great meticulous detail, over the course of more than 500 pages, just what exactly those rules of international legal grammar actually look like in practice, it effectively managed to turn international legal semiotics into a fullblown 'applied science'.

To help illustrate how the logic of discourse-production in international law works, FATU also introduced its readers to three further sets of analytical instruments. The first two of them the one built around the metaphor of ascending and descending argument patterns and the one centred on the dyadic structure apology/utopia - have since received a considerable 
amount of attention in the FATU literature. But, as I am going to show in this essay, it was, in fact, the third of these sets - the one which builds around the old Llewellynian distinction between what may seem discursively justifiable as a legal argument and what is actually going to 'wash' or be argued in legal practice - that captured, ultimately, what was most valuable about FATU's legal-theoretic breakthrough and helped complete the task of marrying the enterprise legal semiotics with that of 'applied legal science'.

\section{FATU's Structuralism: A Point about Intellectual Genealogies}

None of these analytical metaphors, of course, was to be seen as anything more than a convenient heuristic device. And yet every heuristic, in the end, implies a certain set of ontological commitments. The basic ontological commitments which were inscribed in FATU's broader argument all have a clearly identifiable theoretical profile. Although there may be some surface similarities, the operative analytical framework that matches this profile does not trace its intellectual genealogy from the writings of Roberto Unger, Duncan Kennedy, or David Kennedy - what Justin Desautels-Stein calls the 'Harvard school of legal structuralism' ${ }^{24}$ Rather, it is the shadows of Claude Lévi-Strauss and Michel Foucault - the high priests of the French structuralist tradition - that loom most vividly over this part of FATU's intellectual landscape.

To be sure, the footnotes are all still there: the generous reader that he is Koskenniemi does not hesitate to acknowledge time and again his extensive debt to the Harvard circle scholars. ${ }^{25}$ But debts and genealogies are not quite the same thing. The basic intellectual reflexes which guided the evolution of FATU's argument have very little in common with those which have been historically associated with the Harvard structuralist tradition. Indeed, if anything, the latter's general theoretical orientation, on closer examination, appears to have been influenced far more by the legacies of Hohfeld and Llewellyn as

processed and refracted through the early writings of Duncan Kennedy, ${ }^{26}$ than anything one might plausibly include as part of the 'original canon' of the French structuralist tradition. And for all his unquestionably sincere interest in French structuralism, Kennedy's take on the subject was, of course itself in turn deeply over-determined by his personal intellectual circumstances: most notably his longstanding interest in the re-appropriation of the various

\footnotetext{
24 Justin Desautels-Stein, International Legal Structuralism: A Primer, 8 Int Theory(2016)(forthcoming).

25 See, eg, FATU, 10, n.7.

26 See Duncan Kennedy, Form and Substance in Private Law Adjudication, 89 Harvard LR 1685(1976) and The Structure of Blackstone's Commentaries, 28 Buffalo LR 205(1979). See also DuncAn KenNedy, ThE RiSE \& FALL OF CLASSICAL LEgAL THOUGHT Xiv-XXxi (2006)(reviewing some of the historical background surrounding rise of the Harvard legal-structuralist project).
} 
private law heterodox traditions, from Demogue to Fuller, ${ }^{27}$ as well as his protracted ideological struggle against the CLS Marxists. ${ }^{28}$

The difference may seem to be one of mere accent or style, but it is, in fact, very important. The legal-structuralist project elaborated in FATU has a much closer connection to the 'original canon' of French structuralism - as well as a much more strongly pronounced interest in the public law mainstream traditions: Austin, Jellinek, Kelsen, and Schmitt each have a named section in its table of contents - than any AILS work associated with the Harvard circle. What is more, both in terms of its implied ethics and its broader theoretical agenda, the FATU project also seems to be fundamentally uninterested in any kind of Sartrean-style existentialist discussions, not to mention what Duncan Kennedy elsewhere calls the 'organicist tradition' of critical thought. ${ }^{29}$ Both of these themes, on the other hand, have remained central to the intellectual organisation of the Harvard structuralist tradition and can be traced across its canon from the very beginning. ${ }^{30}$

In short, while it seems undeniable that he was greatly inspired by the 'Harvard school', the actual brand of legal structuralism Koskenniemi develops in FATU comes from a fundamentally different genealogy. Even that strange last chapter, where he departs so abruptly from the standard structuralist problematic, seems to have been influenced far more by the non-structuralist aspects of the Harvard circle's legacy: it is Unger's Frankfurt School-style reflections on the possibility of post-liberalism in Knowledge and Politics that leave the most visible traces here, not Duncan Kennedy's Structure of Blackstone's Commentaries. $^{31}$

The reason why it is important to mention this detail is that none of the originators of the French structuralist tradition, of course, was a jurist by training. However brilliant their insights may have seemed otherwise, if the author of FATU were to succeed in adopting their theories for the purposes of constructing a workable account of international law, he first had to find for them a suitable jurisprudential host, a background legal-theoretical framework into which they could be safely transplanted. When the Harvard circle scholars had set out a decade earlier to resolve the same challenge, they turned to Llewellyn, Hohfeld, and the early Fuller. The author of FATU, on the other hand, found his solution in Kelsen's Reine Rechtslehre. ${ }^{32}$

${ }^{27}$ Fuller's work, in particular, seems to have had a very significant impact on the evolution of Kennedy's concept of legal structures. See further Duncan Kennedy, From the will Theory to the Principle of Private Autonomy: Fuller's "Consideration and Form", 100 Columbia LR 94 (2000).

${ }^{28}$ See Akbar Rasulov, CLS and Marxism: A History of an Affair, 5 TLT 622 (2014).

29 Duncan Kennedy, A Semiotics of Critique, 22 Cardozo LR 1147, 1149-57 (2001).

30 A partial exception can be found in David Kennedy's International Legal Structures. But its version of legal structuralism in any event had a much stronger Derridean flavour and, if only in this respect, was fundamentally different from FATU's. For further discussion of that project, see Akbar Rasulov, The Horizontal Mechanism Initiative in the WTO: The Proceduralist Turn and Its Discontents, 6 EYbIEL 61,79-83 (2015).

${ }^{31}$ Supra n.26.

32 Hans Kelsen, introduction to the Problems of Legal Theory (1992). 
Between Low-grade Cynicism and Eclecticism: FATU's Wars against the Anti-Disciplinarian

Agenda in AILS

At the most fundamental level, FATU's emergence as an AILS event can essentially be understood as an intensely powerful reaction against two distinct cultural trends: (i) the ever-deepening anti-intellectualism popularised by the post-1960 generation of pragmatic positivists such as Ian Brownlie, Oscar Schachter, and Louis Henkin; and (ii) light-touch interdisciplinarism expounded by the newly emergent international-law-and-internationalrelations(ILIR) school. ${ }^{33}$

At the heart of the first conflict lay a basic disagreement over AILS's essential disciplinary status: was international law a true academic discipline, on a par with other social sciences, or was it only a vocation? For all their differences, the old generation of international legal positivists - the generation of Kelsen, Anzilotti, and Guggenheim - had at least all shared a fundamental meta-ideological commitment to the idea that international law was a 'real' discipline with a fully-fledged theoretical framework, not just a convenient platform or vehicle for the pursuit of international politics. However much they may have disagreed with one another, each of them vigorously upheld international law's intellectual claims and ambitions and actively defended the theoretical dignity of positivism as a school of thought. To be sure, with the exception of Kelsen, most of them would have never merited inclusion in a textbook on general jurisprudence. But at least their discursive posture had always retained an unmistakable sense of theoretical ambition and they all positioned themselves as self-identifying legal intellectuals who were not afraid to nail their intellectualist colours to their professional masts.

By the mid-1980s, this old ethos had dissipated without a trace. The new generation of positivist scholars, raised on a steady diet of Cold War pragmatism and post-New Haven eclecticism, had lost any interest in ambitious legal-theoretic inquiries. Internalising the cultural self-imagery of a mid-level civil servant, they increasingly sought to dismiss the pursuit of 'theory' - and with it any conversations about international law's academic status - as an essentially frivolous pastime. In a typical turn of phrase, some of them would casually go on to observe that international law was really just another kind of politics, ${ }^{34}$ without bothering to explain how and what therefore made it different from other kinds of politics. Another frequently used rhetorical move would be to declare simply that international law worked $^{35}$ even if nobody could actually agree on the ultimate reason for its bindingness ${ }^{36}$ or identify the exact degree to which it was effective. ${ }^{37}$ In any event, the argument continued,

33 Stephen Krasner, international Regimes (1983); Robert Keohane, After Hegemony (1984).

34 Louis Henkin, 'International Law: Politics, Values and Functions', 216 RCADI 22 (1989-IV).

35 Louis Henkin, How Nations Behave 320(1979).

36 Oscar Schachter, Towards a Theory of International obligation, 8 VJIL $300,302(1968)$.

37 Louis Henkin, The Reports of the Death of Article 2(4) Are Greatly Exaggerated, 65 AJIL 544(1971). 
none of this really mattered: what mattered, rather, was the fact that '[t]here [was] no doubt room for a whole treatise on the harm caused to the business of legal investigation by theory,' which '[w]ith rare exceptions [tends] not only [to] fail[] to improve the quality of thought but [also] deflect[] lawyers from the application of ordinary methods of legal analysis. ${ }^{38}$

For its immediate proponents, this spirit of ardent anti-theoreticism seemed a direct outgrowth of the same kind of down-to-earth practitioner-pragmatism that some twenty or thirty years prior had stood in such good stead for the likes of Lord McNair. To the eyes of a left-leaning Finnish lawyer who had been raised on a steady diet of Kelsen and Ross but also Horkheimer and Adorno, what really stood behind the rise of this new breed of cynicism seemed to be something else entirely. In other fields, the emergence of this sort of antiintellectualist sensibility came to be diagnosed variously as the 'postmodern condition', 'the cultural logic of late capitalism', or the 'disenchantment of formal rationality'. For the author of FATU, however, the answer had a much more familiar face. The rise of pragmatopositivism in contemporary AILS marked for him the arrival into the ILP's internal social space of the culture of Cynical Reason.

The diffusion of the pragmato-positivist sensibility did not only lead to a progressive abandonment of all international law's traditional theoretical ambitions. In the eyes of the FATU project, Brownlie, Henkin, et al. were not simply a group of burned-out old-timers who had lost hunger for 'big ideas'. The elevation of their low-intensity anti-intellectualism to the level of disciplinary standard indicated something far more sinister:

The discontent in our culture has assumed a new quality. It appears as a universal, diffuse cynicism. ... The ancient world knows the cynic ... as a lone owl and as a provocative, stubborn moralist. Diogenes in the tub is the archetype of this figure. In the picture book of social characters he has always appeared as a distance-creating mocker ...

Today the cynic appears as a mass figure: an average social character in the upper echelons of the elevated superstructure. [The] modern cynics ... are no longer outsiders. [They] are integrated, asocial characters who... no longer understand their way of existing as something that has to do with [criticism], but as a participation in a collective, realistically attuned way of seeing things.

Indeed, this is the essential point in modern cynicism: the ability of its bearers to work - in spite of anything that might happen, and especially, after anything that might happen. ... A certain chic bitterness provides an undertone to its activity. For cynics are not dumb, and every now and then they certainly see the nothingness to which everything [they do] leads. ...They know what they are doing, but they do it [anyway]. ${ }^{39}$

38 Ian Brownlie, Recognition in Theory and Practice, 53 BYIL 1( 1982).

39 Peter Sloterdijk, Critique of Cynical Reason 3-6(1987) 
FATU's most important fight, in the end, however, was not against Brownlie and Henkin. They may certainly have been at the top of its author's list of principal academic targets when the project had been first conceived. But they did not, ultimately, become his main antagonists. Nor for that matter did their ideology of lowgrade cynical anti-intellectualism prove the most significant challenge that confronted the discipline of AILS at the end of the Cold War. That dubious honour, rather, belonged to another scholarly movement: the newly created, self-declaredly interdisciplinarian ILIR school. ${ }^{40}$

Like the pragmato-positivists, ILIR scholars shared a number of traits which from the perspective of the traditional aesthetics of legal science appeared indistinguishable from intellectual nihilism. What separated them from the pragmato-positivist crowd was the fact that they seemed ready to extend the exact same kind of cynical instrumentalism which the latter applied to individual legal categories and legal regimes, to the very idea of law's disciplinary sovereignty over its own intellectual materials. Stripped to its basics, the central argument of the ILIR approach stated that international law - both as a political regime and as an academic discipline - stood to gain a considerable amount of practical empowerment if it were to import as part of its operative conceptual framework a theoretical apparatus developed by IR scholars and subordinate its broader reasoning protocols to the analytical regimen imposed by the IR discipline.

Both then and today the most obvious reaction available to the mainstream international lawyers in the face of such an aggressive programme of disciplinary denigration would have been to interpret the rise of ILIR as the direct application by US-based international law scholars to the US-focused segment of AILS of the same strategic blueprint which the USbased law-and-economics scholars first developed in the context of the US domestic legalacademic scene. Another equally tempting solution would have been to read the advent of the ILIR approach as the proverbial return of the prodigal son. On this view of things, the gradual expansion of interest among IR-trained scholars in the subjects of international regimes, transgovernmental cooperation, international institutions, and international normproduction was really just a sign of IR's inevitable return to the idea that 'law matters'.

Whatever one may think about the justifiability of these interpretations, neither of these responses, in the end, appeared satisfactory to the author of FATU. Writing a decade-and-ahalf after the first edition of FATU, he would come to recognise the rise of ILIR as the symptom of a far more sinister development in the history of international law's disciplinary decline as an intellectual enterprise than anything ever proposed by Brownlie or Henkin. The 'culture of dynamism' that the ILIR scholars sought to bring to international law's dry epistemic quarters, he would now argue, was something more than just an attempt at an epistemological intervention: it was a façade for the argument for 'the ultimate irrelevance of law' and the denial of the most basic values of the Enlightenment: freedom, equality, 'openness to what others have to say'. ${ }^{41}$ Pushed to its extreme, its programme of eclectic

40 Kenneth Abbott, Modern International Relations Theory: a Prospectus for International Lawyers, 14 YJIL 335 (1989); Anne-Marie Slaughter Burley, International Law and International Relations: A Dual Agenda, 87 AJIL 205 (1993); Anne-Marie Slaughter, 'International Law and International Relations', 285 RCADI 9 (2000).

41 Martti Koskenniemi, Gentle Civilizer of Nations 500-1 (2001). 
interdisciplinarism led its followers to a heady mix of cynicism and moral pathos that was 'only a step removed from underwriting the preferences of the Western foreign policy elite. ${ }^{42}$

Coming on the tails of pragmato-positivism's renunciation of AILS's traditional theoretical ambitions, ILIR's dismissal of international law's indigenous theoretical apparatus as being de facto 'unfit for purpose' threatened to bring AILS as a discipline to the precipice of complete political and intellectual self-annihilation. If such a disastrous outcome were to be prevented, followed the inevitable conclusion, a most robust counteroffensive had to be launched.

The 'aggressor' whose attacks were to be defended against was not hard to identify: the ultimate source of both pragmato-positivism and the ILIRian deviation was the same diffuse cultural trend that had been described by Lyotard a decade earlier. It was postmodernism 'what dunnit' in FATU's eyes and there was no time to beat around the bush:

As international lawyers, we have failed to use the imaginative possibilities open to us. We became suspicious of theory because it made claims of comprehensiveness and normativity which it could not sustain. Our practice [as a result became] marginalized ... Instead of impartial umpires ..., we were cast as players in [somebody else's] game ... It is not that we need to play the game better, or more selfconsciously. We need to re-imagine the game [and] reconstruct its rules. $^{43}$

So far, so good, but notice now an important detail. Having arrived at this conclusion, Koskenniemi does not proceed to draw from it the same set of take-aways as most other AILS traditionalists. ${ }^{44}$ Since it was not the postmodernism of theory that lay at the root of international law's malady, but the postmodernism of practice, writing angry diatribes against relativism, nihilism, and decisionism was not going to accomplish anything useful. If the source of the problem lay in the de facto postmodernization of AILS's disciplinary culture, then the only effective response to that was to start an opposing project of cultural re-engineering: the key, to go back to Lopez-Medina's useful distinction, was to target international law's discourses of 'pop jurisprudence', not the rarefied conversations of professional legal theorists.

What did all of this mean in concrete terms? To anyone steeped in the Frankfurt tradition, the answer was perfectly obvious: the end-goal was to create a new internal ideology for international law as a disciplinary enterprise to be internalised with equal effectiveness both by the academic and the practitioner segments of the ILP. What this translated to in terms of concrete strategy, for the author of FATU, ultimately, came down to two main points: (i) the

42 Martti Koskenniemi, 'Legal Universalism', in SinkWAN CHeng, LAW, Justice, AND POWER 46, 59(2004).

${ }^{43}$ FATU, 561.

${ }^{44}$ Compare Oliver Gerstenberg, What International Law Should (Not) Become: A Comment on Koskenniemi, 16 EJIL 125(2005); Pierre-Marie Dupuy, Some Reflections: A Response to Martti Koskenniemi, 16 EJIL 131 (2005). 
final objective was to trigger a radical shift in the (newly) established consensus about international law's 'disciplinary ethics'; and (ii) the best way to achieve this was to induce the emergence of what in his later writings he would call the 'culture of formalism' but which at this point would probably be much more accurately described as a culture of unashamed disciplinarism, or to steal a line from Althusser, a culture of unashamed antianti-disciplinarism.

But what does it take to pull off something like that in practice? How does one trigger intradisciplinary cultural shifts in professional legal communities? What does one need to do to cause a cultural revolutionof that kind? Koskenniemi's answer to this challenge can be deduced from the general structure of the FATU narrative itself. The first step, evidently, was to articulate a new concept of international law's objective identity as a matter of formal theoretical statement. The goal was to show through a careful and explicitly theoreticist argument international law's fundamental uniqueness and singularity as a system(in the Luhmanian sense of the term). In the context of the book's narrative, this task is performed by Chapter 1 . Given that international law's disciplinary culture resides not at the level of 'high legal theory', but at the level of pop jurisprudence, the next step in the strategy was to entrench this newly unveiled concept by putting it into practice. The essential task at this point was to demonstrate the fundamental effectiveness of the new theory by illustrating its practical applicability over and over, across as many areas and contexts as possible - treaty interpretation (Chapter 5.2), recognition of states (Chapter 4.6), territorial disputes(Chapter 4.7), NIEO(Chapter 7.2), the law of custom (Chapter 6), the writings of leading authors and publicists(Chapters 2 and 3), etc.

A relatively uncontroversial 'war plan', all things considered. But controversy - like brilliance and genius - in legal scholarship rarely comes through at the level of general plans. It was not so much the basic contours of what it tried to pull off but the particular manner in which it went about doing it which gave the FATU project its distinctive identity: the key to reverting the course of international law's cultural postmodernization for the author of FATU was to produce a distinctly modernist account of the international legal reality by deploying a distinctly modernist - from the point of view of legal scholarly practices - discursive move. Having been raised in a tradition of legal thought focused so prominently around Kelsen and Ross and having been exposed for such a long time to the writings of Frankfurt scholars and the French structuralists, in retrospect it seems only logical that when it came to deciding on the means by which to prosecute his 'war plan' against international legal postmodernism, the author of FATU would elect to publish a book whose message was built on the same intellectual platform as the old Kelsenian project of 'pure legal theory' and verbalised in the neo-Saussurean vernacular of Levi-Straussian uber-formalism.

It seems logical and self-evident now - but think how strange and dubious this strategy must have seemed in the context of its times! To save international law from postmodernization, to restore the discipline's sense of theoretical dignity and intellectual ambition by marrying Kelsen and 'high French theory' - what was he even thinking?

FATU on the Inner Mechanics of International Law: Positivism with a Structuralist Twist 
The first tenet at the heart of FATU's new theoretical framework was also its most intellectually conservative element. In its general contours, it can be considered a direct logical extension of the old positivist thesis that 'all legal constructs are manmade'.

Every species of legal constructs - of which positivism knows three basic varieties: legal concepts, rules, and doctrines - is a product of human creation. That is to say, every object which is used or reflected upon in the course of legal reasoning that is not a rule of formal logic is a posited imaginary. It has no objective source outside the legal domain. It cannot be derived from the 'natural state of things', nor from the inherent structures of 'pure reason'. What is more, it has no correlating counterpart in the world outside the legal domain either. There is no such 'thing', outside law, as a 'trespass', a 'corporation', or a 'closed multilateral treaty'. Even if one should recognise as a matter of objective reality the existence of various corresponding patterns of social and physical events to which these categories may be applied for the purposes of legal analysis, the process of this application would not, on this view of things, ultimately be decided by the objective qualities of those events themselves but by the conditions of the respective part of the legal domain.

The idea that all legal constructs should be treated as imaginary fictions is not, of course, very novel, but it has two important theoretical implications for the purposes of the FATU project. In the first place, as already suggested, it indicates that we can't, ultimately, find any objective reality behind any given set of legal concepts, rules, or doctrines that are used in international law that will be independent of the collective imagination of the ILP which has called these constructs into existence. In the second place, it indicates also that none of these constructs can have any inherent or self-evident meaning: from an ontological point of view, they are all just imaginary artefacts created by international lawyers to help describe whatever discernible regularities in the organisation of the respective set of legal processes these lawyers are used to distinguishing and investing with significance when talking among themselves.

Like empty universals in nominalist philosophy, rules, concepts, and doctrines do not have any fixed external referents or fixed internal cores. There is, consequently, nothing perpetual, privileged, or objective about their content: they are all empty floating signifiers as Ernesto Laclau would have said. The only thing which really exists 'out there' when we speak about the doctrine of state immunity, a right of innocent passage, or the concept of actionable subsidy in the law of the WTO is just a series of relatively stable patterns of analytical classification according to which the respective groups of international lawyers order and administer the relations among the respective subjects of international law. None of these patterns exists outside the collective mind of the ILP; none of them, furthermore, is governed by any kind of external or internal logic. What sort of content may be included under any of these rubrics can never be established in abstracto. Nor can it be fixed conclusively and permanently. The configuration of every pattern (and thus the semantic content of the corresponding construct) will always remain arbitrary and capable of shifting at any given moment.

In traditional European jurisprudence, this way of thinking is most frequently identified with the idea of legal positivism. In the broader history of legal thought, however, this set of ideas 
has also been described in the past under the rubric of functionalism. ${ }^{45}$ Functionalism in its standard formulation is essentially a school of thought based around two basic sets of assumptions. First, the reality of every abstract social construct, such as, say, money, sovereignty, or territory, consists only in the scope of its present practical functionality: 'money is what money does', 'a rose by any other name', etc. Second, the concept of 'functionality' here has to be understood in the sense of whatever set of conditions and consequences the broader system of social processes in the context of which the given construct is currently used normally comes to associate with it. To go back to our earlier example: a treaty is that whichever in the context of the contemporary international legal practice acts and functions like a treaty; the meaning of 'state immunity' is found solely in those conditions and consequences which are associated with the use of this construct in contemporary international legal practice; the doctrine of anticipatory self-defence has precisely that content which the contemporary system of international legal practice has come to assign to it, and so on and so forth.

Note an important nuance: which particular set of functions a given legal construct will be assigned can never be determined ex ante and in abstracto. Functions are not an intrinsic component of the objective reality: they do not exist, like Kantian objects, in-themselves. They belong, rather, in the category of observer-defined attributes: they are something that we create through the power of our intersubjective consensuses. ${ }^{46}$ Given that an intersubjective consensus in practice can only form as part of some background set of shared collective expectations, it follows from this that every function can essentially be understood as an individuated articulation of some larger, pre-existing collectively shared frame of reference which is itself neither a reflection of some natural order of things nor a projection of pure formal logic, but is rather a product of an entirely conventional origin.

It should not be too difficult to recognise where this line of reasoning leads. Thus posed, the idea of legal positivism/functionalism on some basic level becomes effectively synonymous with Saussurean semiotics: what one tradition sees as functions, the other calls signifiers; what one thinks of as the use of legal constructs, the other describes as parole; the system of the underlying communal expectations shared by the participants of the international legal process becomes langue, the idea that legal constructs only make sense within the context of legal domain seamlessly morphs into the thesis that meaning is created through difference not reference, and so on and so forth.

In its opening pages, FATU declares:

[the argument proposed here relies on] a certain vision about the meaning of (legal) concepts. ... Meaning is not(as we commonsensically assume it to be) present in the expression itself. ... The sense of an expression is not determined 'from the inside' but by the formal differences which separate it, make it different from other expressions in that langue. Meaning is relational. ${ }^{47}$

\footnotetext{
45 Felix Cohen, Transcendental Nonsense and the Functional Approach, 35 Columbia LR 809(1935).

46 John Searle, Construction of Social Reality 9-23(1995).

47 FATU, 8-9.
} 
At the end of the book Koskenniemi returns to the same theme again: 'There is ... no "objective" meaning to the linguistic expressions of rules.' 48 'We cannot convince someone who disagrees with our interpretation by referring to the correspondence between our interpretation and the expression's "real" extraconceptual meaning. ${ }^{49}$

The reason why we should pay attention to this fact, explains Koskenniemi, is obvious: all throughout international law's history every pursuit of disciplinary identity has been fuelled precisely by this discovery. Every attempt to articulate the essence of the 'juristic method' turns eventually into the quest to find an 'impartial guarantor' of meaning, 'a solid epistemological foundation'. ${ }^{50}$ But in a world that no longer believes in theology, every such quest inevitably ends the same way: any form of interpretive stability in an international legal system can only be achieved through the conventional stabilisation of the respective aspects of the interpretative process, that is to say, through the ossification of the underlying communal consensuses within the ILP through the mechanism of social conventions. Inasmuch as there exists any kind of 'autonomous' order of international legal ideas, it always remains 'firmly embedded in international legal education and the professional self-understanding of international lawyers' and nothing more mysterious or grandiose than that. It is this fact - and this fact alone - that 'establishes the identity of the legal field' and gives its accompanying conceptual materials their fundamental structure. ${ }^{51}$

The second principal tenet at the core of FATU's legal-theoretical framework can also be understood as a variation on a traditional positivist theme. Its central point of reference comes from an idea which in other fields of legal study has come to be known under the rubric of the bundle of rights tradition. ${ }^{52}$

The argument that legal constructs don't have any fixed essences behind them is often understood as simply suggesting that all legal constructs are semantically unstable. A more accurate interpretation, however, would be that the reason why legal constructs don't seem to have any fixed objects behind them actually comes from the fact that every such object in reality is not a single monolithic entity but a composite arrangement of structurally discrete elements - or to be more precise, a speculative claim about such an arrangement.

Whenever international lawyers make appeal to the concept of state immunity or invoke the doctrine of pari passu or the right of national treatment, what they really do in practice, according to this view of things, is just put forward a certain vision about how the corresponding cluster of international relations ought to be, in principle, configured. They argue, in other words, about how the respective package of what in Hohfeldian terms one

48 Ibid. , 531 .

49 Ibid.

50 Ibid. , 521

51 Ibid. 534 .

52 Joseph Singer, Entitlement 9-13 (2000); Stuart Banner, American Property 45-80 (2011). 
would call rights, duties, liberties, and no-rights(RDLN) are, have been, or ought to be, distributed among the respective legal actors.

Every legal construct, on this view of things, essentially only constitutes an argument about how the respective package of RDLN ought to be configured. Its ontology, in other words, is not that of an ontological fact but only of a purported statement about it: a legal rule is not a constituent element of some invisible larger whole that exists independently and objectively (the law-in-itself) as a collection of such kind of elements. The linguistic usages we have developed - 'the Court's judgment clarified the meaning of rule $X^{\prime}$ ', 'the new treaty extended the scope of principle $Y^{\prime}$, 'the respondent challenged the applicability of doctrine $Z$ ' - often invite us to think otherwise. But this is all just an illusion: in reality each of these usages is nothing more than a convenient pragmatic device that helps us to simplify the process of articulating our discourses. The actual ontology of international law consists in the fact that rules, concepts, and doctrines don't formally exist in or as themselves, ${ }^{53}$ i.e. separately from the imaginative games played by the ILP. ${ }^{54}$ That is to say, what actually comes into existence each time we speak of, say, the creation of a new legal rule, the application of a doctrine, or the invocation of a concept, is just a shift in the arrangement of that posited imagined reality which the ILP operates and inhabits.

Push this idea to its logical conclusion and what you get is another standard Saussurean thesis: in ontological terms, every legal rule constitutes nothing more than a heavily encoded, ostensibly descriptive statement concerning the best way to distribute a certain bundle of RDLN among a respective group of legal actors. What makes this kind of statements special from the linguistic point of view is that they seek to portray the respective bundles as hypostatized entities. Thus, instead of 'admitting' that the provision captured in Article 51 of the UN Charter seeks only to propose a certain distribution of RDLN, the rules-centric linguistic tradition adopted by the ILP suggests that we imagine that this provision represents the existence of a certain objective entity: the rule of Article 51.

The same logic which applies to rules also applies to doctrines: whenever we speak about doctrines what we really have in mind is just another set of similarly encoded statements. The only difference is that of the formal order of abstraction: if legal rules are first-order statements about RDLN, doctrines are second-order statements. Every time we discuss the meaning or the applicability of, say, the doctrine of the permanent sovereignty over natural resources or $\mathrm{R} 2 \mathrm{P}$, what we really do in practice is just put forward arguments about how best to organise the respective clusters of international legal rules, i.e. how to distribute the respective sets of first-order statements about the underlying bundle of RDLN.

Now, all this may seem abstract and vague, but watch now where this line of thought takes us next. From the traditional positivist point of view, a legal concept would be the term we would use to describe those semantic blocks which lawyers recruit to help develop and articulate their understanding of the respective sets of legal rules and doctrines, i.e. to articulate the respective statements about the underlying bundles of RDLN. So far, so very

\footnotetext{
53 FATU, 568-9.

54 'Law is what lawyers think about and how they go about using it in their work'. Ibid., 569 .
} 
Kelsenian, but note now what happens when we process this idea through the Saussurean filter. Since no semantic block, per Saussure, can perform its function as a semantic block when it is taken in isolation from other similarly positioned semantic blocks, it follows that every legal concept rather than being seen simply as an instrument for the articulation of legal rules and doctrines should be understood, in fact,also as a certain kind of encoded statement, i.e. as a dynamic act of socially-grounded discursivity rather than a static entity that exists in some transcendental fashion.

The next question to ask at this point then becomes: an encoded statement about what? Given the fact that the ultimate purpose of every legal concept, as noted earlier, is to help us articulate the respective sets of legal rules and doctrines, it follows, logically, that the object of each legal concept(taken as a statement), inevitably, has to be an argument about how those rules and doctrines(each of which is also a statement) are distributed and related to one another. Put differently, every time we invoke a given legal concept, what we really do in practice is just put forward a series of statements about how another series of statements should be understood.

Let us pause for a moment here and retrace our steps.

1. Note, for starters, what this sequence of observations has done to the traditional operative concepts of legal positivism. Note what has appeared and what has disappeared from the traditional positivist ontology after we have worked our way through this analysis. Disappeared: static constructs(rules, doctrines, and concepts as hypostatised entities). Appeared: dynamic actions(statements). Disappeared: any fundamental distinction between rules, doctrines, and concepts. Appeared: awareness that everything in law is just one single, messy process/field of discursivity. Disappeared: any room for the idea that a legal order can exist in- or by itself, separately from the legal profession. Appeared: awareness that everything that exists in law exists because of and through the demands of whatever social processes occur within the legal profession.

2. Rules are statements about RDLN. Doctrines are statements about rules. Legal concepts are statements that we use to develop statements about rules and doctrines. Rights, duties, and liberties are all legal concepts. Put these four thoughts together and what emerges is the idea that every legal construct used in international law is ultimately a product of the exact same source. Everything that on its surface seems to be a representation of a 'thing that is' in reality is only a statement about 'what that thing may be'. Push this idea a little further and what you get, eventually, is the notion that even though it was said earlier that every rule, doctrine, and concept is actually just an encoded statement about the respective bundle of RDLN, what we really should have said was that every rule, doctrine, and concept is actually an abstract continuum of possible statements regarding that bundle. Every deployment of a legal concept, doctrine, or rule in international law is a coded invocation of a certain vision - one among many visions that could be invoked at this point - of the underlying bundle of RDLN. Inasmuch, furthermore, as every such deployment is different in its intention and content from other deployments, this means in practice that: (i) no legal concept, doctrine, or rule can have its precise legal meaning fixed in abstracto because every invocation of it will automatically entail a certain reconfiguration of its contents; and (ii) it doesn't make any sense to focus on contesting or excavating the 'general meaning' of such 
constructs, since the real dynamic is always going to be played out at the level of the underlying bundles of RDL. Or, to put it slightly more bluntly, concepts, doctrines, and rules don't carry any practical meaning in law, only the respective RDLN bundles do, and each of these bundles itself, in the end, is nothing more than a normative proposition about the distribution of power within a respective cluster of international relations.

Once again the extent of Kelsen's influence on FATU's thought-world is difficult to overlook or overestimate. From his remarks on the inter-permeability of law-application and lawmaking(both are just forms of making an argument about how the respective regime of RDL ought to be structured) ${ }^{55}$ to his discussions of 'frames of possibilities'(every legal norm 'exists' only as a range of plausible interpretations and it is at this level that the practical reality of law-application unfolds), ${ }^{56}$ Kelsen's conceptual framework peeks out from behind every corner.

The secret of becoming a good legal professional, declares Koskenniemi at the end of FATU, lies in accepting the phantasmal character of all legal constructs. In practice, this entails

a refusal to engage in discussions about general principles ... Rather than be normative in the whole [one] should be normative in the small. [One should] attempt, to the best of [one's] capability, to isolate the issues which are significant in conflict, assess them with an impartial mind and offer a solution which seems best to fulfil the demands of [one's situation]. ${ }^{57}$

The argument against the reification of omnibus concepts and monolithic categories has a long pedigree in modern jurisprudence. It also has a rather extensive history of criticism associated with it. Giving up on the idea that abstract concepts and normative principles such as 'justice' or 'non-intervention' do not have any legal effectivity and should not therefore be invested with any emancipatory expectations has long been identified as the guaranteed recipe for closing off any spaces of dissent and entrenching tyranny. Does the switch to the 'bundle-ist' way of thinking about international law not bring with it a certain form of disempowerment? Once more FATU offers its readers no easy answers:

Does [it not] imply losing a commitment to the whole, to peace and world order? No, but it does force us into seeing that commitment in a new light. It is not a commitment which seeks to realize given principle or ready-made social arrangements. [Rather i]t aims to construct the whole as a structure of open political conflict and constant institutional revision. The whole [which is international law is] a system [of] particularized solutions. ... Beyond [this,] it makes no pretention to offer principles of the good life which would be valid in a global way. ${ }^{58}$

55 See hans Kelsen, General Theory of LaW And State 133-5 (2006); Kelsen, supra n32, 70 .

56 Ibid. , 80.

57 FATU, 555.

58 Ibid., 556. 
FATU's third main tenet is a direct extension of the same credo of relentless antifoundationalism. Statements about RDLN, it argues, don't really exist 'in themselves', but only as the actualisations of a certain 'frame of possibilities' that is put in place by the respective paradigm. Every legal concept, doctrine, or rule, in the final analysis, constitutes not so much a statement about the respective bundle of RDLN, as a representation of a certain range of possible normative contestations within which such statements are developed and actualised.

All rules, doctrines, and concepts known to international law are just statements whose objects of references consist of other statements. Scratch the surface of international law's self-presented reifications and you will find nothing there other than an endless, chaotic process of interpretative clashes, projections, contestations, and speculations. Everything is in flux and nothing is static. Not even the boundaries that are meant to separate one 'frame of possibilities' from another can be said to be stable. Indeed, taken to its logical conclusion, FATU's theory of law inevitably brings us to the conclusion that the only factor that can be said plausibly to separate the process of normative contestation surrounding, say, the principle of non-intervention from that surrounding the duty of national treatment is the appearance of a general differentiation in the purported identities of the respective 'objects' of reference at the centre of the respective contestational processes. The interpretative contestations behind 'non-intervention' have as their purported object of discussion/production the meaning of 'non-intervention'; the interpretative contestations underlying 'national treatment' have as their object the meaning of 'national treatment'. Beyond this, there is nothing.

Seen from this angle, FATU's intellectual enterprise turns effectively into an argument for the recognition of the essential unavoidability of ontological fizziness. Behind every legal concept, doctrine, or rule lies not just a certain vision of how the respective bundle of RDL ought to be arranged and distributed, but an endless cascade of multiple different visions that constantly change their content, focus, and intensity - and there is nothing we can do to repair or end this state of affairs. The point may seem sufficiently abstract at first to justify being classed as a purely theoretical insight, but it is here, in fact, I believe, that we finally begin to arrive at FATU's applied-science moment.

The thesis that international law can be understood as a system of pure discursivity has long been a part of the received wisdom for various segments of the international legal academy. What FATU does to it in this part of its argument - to use a fancy post-structuralist label - is put it conceptually sous rature. That is to say, it simultaneously deploys this idea 'at its face value' and at the same time actively disproves it by showing its fundamental unsustainability. For what may seem at first glance a formal field of pure discursivity, it argues, is in reality nothing like that at all: peer long enough and what you will discover behind this fake façade of emotionless reasoning is a mad, never-ending scramble that has no internal logic, no aim, no pattern, no rationality, nor any sense of a pre-determined outcome. And yet for all its frenzied and chaotic character, it adds immediately, there can still be found in this endless scramble a certain sense of immanent rhythm which helps, in the final analysis, make it both generally intelligible and practically manageable for every 
professionally trained international lawyer. It is this rhythm that he has in mind to teach his readers when he sets out to discuss with them the 'grammar of the international legal argument': a rhythm at the root of which he posits lies a certain set of 'quasi-physical' laws.

The Inner Life of International Law: FATU's Theory of the Rules of Engagement for the

\section{Conduct of International Legal Argument}

Again, the main idea here may not seem very novel. At some level it just seems to be an extension of the old Kelsenian thesis that insofar as every act of applying or interpreting a given legal rule inevitably leads to the act of implicitly creating a new rule ${ }^{59}$ the business of legal interpretation is, in principle, indistinguishable from that of legislative advocacy. The practice of 'saying how things are' is essentially the same as 'arguing about how they ought to be'. But what sort of arguing are we talking about here? In the Harvard structuralist tradition, the usual answer to this question would be 'policy reasoning': a practice that is defined as the production of 'argument[s] in favour of or against a particular resolution of a gap, conflict, or ambiguity in the system of legal rules' or the understanding of a legal concept or doctrine that make appeal to some broader systemic values, such as formal realisability or institutional competence, or some substantive, quasi-moral ideals, such as self-reliance or good faith. ${ }^{60}$

The explanation offered in FATU takes a slightly different angle. Instead of conceptualising the phenomenon in question as a species of moral reasoning or a discourse about institutional design, the FATU approach explains it as a discourse that (i) looks from the proposed interpretations of the contested constructs 'to their underlying reasons'; and (ii) in doing so invites us to make a choice between a number of otherwise equally valid normative interpretations. $^{61}$

Every valid statement in contemporary international law, argues FATU, has to be supported by a justificatory argument constructed according to either what it calls the ascending model or the descending model. ${ }^{62}$ In the former case, the proposed interpretation of the given legal construct is put forward on the grounds that it would best fit with the existing patterns of state practice; in the latter, because it would supposedly best promote the achievement of some broader value, such as due process or human dignity, or some other fundamentally important principle recognised by international law.

Because of the way international law's intellectual culture has developed over the last two centuries, both the ascending and the descending strategies are recognised today as disciplinarily valid. ${ }^{63}$ This means that at every given point in the construction of our argument we can resort to either one of them with equal legitimacy. The tricky part,

59 KELSEN, supra n.32,70.

60 Duncan Kennedy, Semiotics of Legal Argument, 42 Syracuse LR 75 (1991) (italics added).

61 FATU, 591.

62 Ibid. 59.

63 Ibid., 575. 
however, is that 'the two patterns ... are ... mutually exclusive' ${ }^{64}$ As a result, every time we put forward an argument constructed according to one pattern, it will be possible immediately to challenge it by demonstrating its fundamental incompatibility with the other pattern and vice versa. What is more, even if we decide to diversify our approach by assembling our argument as a bundle made of several different argument-blocks, the problem is still going to remain: inasmuch as every individual block will remain formally severable from the rest of the argument-bundle, a sufficiently skilled opponent will only have to figure out how to disassemble this bundle into its constituent blocks before attacking each block constructed according to the descending logic by showing its fundamental incompatibility with the ascending model, etc.

What is the practical relevance of all these observations? Recall what has been noted earlier:

(i) every legal construct 'in reality' exists only in the form of the corresponding set of arguments about the respective bundle of RDLN;

(ii) there exists no natural logic which dictates how each RDLN bundle ought to be configured in practice;

(iii) every legal construct can also be understood in practice as the representation of a certain segment of that mad, never-ending scramble of normative contestation which constitutes the living reality of the international legal discourse;

(iv) the practice of normative contestation in international law has an internal structure: there exist only two valid approaches to constructing justificatory arguments in international law, they are mutually incompatible but also equally valid in terms of their systemic legitimacy, against every descending argument, it will always be possible to construct an ascending counterargument and vice versa.

Put these four ideas together and what you get is the simple but very powerful insight: every legal concept, doctrine, and rule used in modern international law can be understood, for ontological purposes, not only as the representation of a certain segment of normativecontestational process, but also as a crystalline-style structure of strictly ordered antagonisms. ${ }^{65}$ Each branch of this crystalline structure represents a site of potential contestational eruption, i.e. a pre-structured rhetorical space for the conduct of interpretative scrambles governed by the rules of engagement described in thesis (iv) above.

Every argument-block constructed according to the rules of the ascending approach can be critiqued from the point of view of the descending approach and vice versa. Since we cannot consistently privilege either approach over the other, every argument we construct in practice will have to become a bundle comprised of a series of differently-modelled argument-blocks.

The more the argument-bundle includes both utopian and apologist argument-blocks, the more self-contradictory its overall justificatory basis will become, the more vulnerable, in

64 Ibid., 42.

65 Cf. J.M.Balkin, The Crystalline Structure of Legal Thought, 39 Rutgers LR 1(1986). 
consequence, the interpretation we will be putting forward will be to what in the old CLS vocabulary was called 'trashing' operations. ${ }^{66}$ It doesn't take any special skill to trash an argument-bundle. Every skilled lawyer with a minimum of training can in principle trash any number of argument-bundles, no matter how skilfully designed and put-together. All that one has to do is simply disassemble each given argument-bundle into its constituent argument blocks and how to identify the operative identity of every block in terms of its descending/ascending mechanics; beyond that, it is all just a question of practice and experience.

Consider the placement of the emphasis, though: just because 'in principle' there exists the possibility that every descending argument-block will be trashed from the ascending position and vice versa, it does not at all follow that this possibility is necessarily going to be used. Some lawyers will simply lack the knowledge of the relevant precedential material to give their skeleton (counter-)arguments the necessary legal flesh; others will not be able to afford the political costs associated with endorsing certain argument lines.

Not everything that can be challenged, in other words, will be challenged. At the end of the day, notes FATU, the process of trashing, like that of reaching a consensus, is governed by a purely social logic, and there exist no inherent legal criteria that dictate when and how social logics will play out. ${ }^{67}$

Behind every legal construct there extends a certain field of normative-contestational possibilities whose outer limits coincide with the limits of its potential interpretability. The shape of this field can be identified in abstracto through the study of the juridical-conceptual structure of the applicable legal materials and the technical understanding of the workings of the ascending/descending patterns structure. What cannot be so identified, however, is just how much of that field will actually be usable (and used) in practice at particular points in history. Answering this sort of questions, however, falls, for FATU, far outside the proper province of legal studies: when one reaches this point, the 'grammar' of the international legal discourse inevitably collapses into its 'social world', ${ }^{68}$ and about that there is nothing more for legal science to say. ${ }^{69}$

Note the obvious symbolism of the proposed formulation: 'grammar' versus the 'social world'. What we are witnessing here, in effect, is the ultimate divide between Kelsen and Holmes, the point where the strict formalism of European legal science meets the solutionsoriented eclecticism of American legal realism.

Note how pithily FATU formulates the theoretical location of this meeting point. Note also on which side of this divide it chooses to position itself. ${ }^{70}$

\footnotetext{
66 Mark Kelman, Trashing, 36 Stanford LR 293 (1984).

67 FATU, 598.

68 Ibid. ,596-8.

69 Cf.Ludwig Wittgenstein, Tractatus Logico-Philosophicus 89 (2002): 'What we cannot speak about we must pass over in silence.'

70 FATU, 589: 'the descriptive project of [this book] is not an account of how legal decisions are made - it is about how they are justified in argument.'
} 